\title{
Dégradation de alphas, bêta et kappa-caséine par la suspension de germes des bactéries de la fermentation lactique
}

\author{
par \\ J. RYMASZEWSKI, S. POZNANSKI \\ et \\ M. MARKOWICZ-ROBACZEWSKA \\ (Institut du Génie et de la Biotechnologie Alimentaire \\ de l'Université Agricole d'Olsztyn-Pologne)
}

La connaissance de l'activité protéolytique des souches diverses de bactéries lactiques a une importance essentielle dans la sélection des cultures de fromagerie.

Comme il résulte des données d'Amunstadt [2], de Van der Zant et al. [22], de Poznanski et al. [13] des ferments lactiques possèdent un pouvoir limité de la dégradation directe de la caséine ; ils sont pourtant capables de fermenter des produits intermédiaires de la dégradation de la caséine par la présure. En même temps, on a constaté que la plupart des bactéries lactiques possédaient deux sphères optimales de l'activité protéolytique, l'une à $\mathrm{pH} 5,5$ et l'autre à $\mathrm{pH} 7,0$, l'activité protéolytique des enzymes qui agissaient à $\mathrm{pH} 5,5$ ayant de l'importance pratique pour le procédé régulier de la maturation des fromages.

Dans leurs études sur le procédé de la dégradation des fractions diverses de la caséine, influencé par des préparations enzymatiques qui avaient été obtenues à partir des germes de bactéries lactiques, Poznanski et al. [13] ont constaté que la fraction $\chi$ de la caséine était protéolysée à $\mathrm{pH} 5,6$ avec l'intensité la plus élevée, tandis que la protéolyse des fractions $\beta$ et $\alpha_{\mathrm{s}}$ étaient moins intenses. Par contre, Dyatchenko et al. [6] soutiennent que c'est la $\beta$-caséine qui est hydrolysée de la manière la plus intense par des enzymes des bactéries lactiques.

Dans les études préliminaires que nous avons faites [15] sur la décomposition de la $\chi$-caséine effectuée par la suspension de germes des bactéries lactiques dans l'intervalle du $\mathrm{pH}$ de 5,0 jusqu'à 7,0 , nous avons constaté que cette fraction était dégradée par des souches 
diverses avec une intensité variable, le degré de protéolyse dépendant du $\mathrm{pH}$ du substrat. C'est pourquoi nous avons résolu, dans cet ouvrage, de suivre la courbe de protéolyse de la caséine isoélectrique

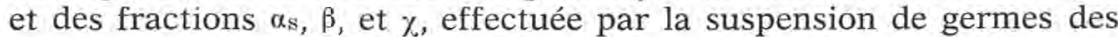
souches définies des ferments lactiques, par rapport aux valeurs de $\mathrm{pH}$ du substrat.

\section{PROTOCOLE EXPERIMENTAL}

Pour nos études, des suspensions de germes étaient préparées à partir des trois souches qui entrent généralement dans la composition des levains lactiques. C'étaient : Str. lactis $\mathrm{T}_{1}$, Str. diacetilactis 157 et Str. cremoris 319 ; les germes microbiens étant obtenus par le procédé de la culture stationnaire, avec agitation continue et ajustement périodique du $\mathrm{pH}$ du milieu à 5,9-6,5. Le lactosérum hydrolysé partiellement avec la papaïne, et enrichi par addition de l'extrait de levure et d'ions de Mn, servait de milieu. Celui-ci était préparé selon la méthode de Valles et Mocquot [20], modifiée par nous-mêmes [16]. Les germes des bactéries diverses étaient multipliés aux températures qui étaient les plus favorables à leur développement.

Après la durée définie de la propagation, les germes de bactéries étaient séparés par centrifugation pendant $30 \mathrm{mn}$ à $6000 \mathrm{t} / \mathrm{mn}$ (1000 g). Ensuite, ils étaient lavés avec la solution tampon de phosphate à $\mathrm{pH} 7,0$ pour éliminer les restes de lactose. Enfin, ils étaient mis en suspension dans la même solution et refroidis à $5^{\circ} \mathrm{C}$.

Comme substrats d'essai, des solutions de la caséine isoélectrique et des fractions de la caséine $\alpha_{s}, \beta$ et $\chi$ à 1 p. 100 furent employées dans nos études. La caséine isoélectrique était préparée d'après Ribadeau-Dumas et al. [14], la fraction $\alpha_{s}$ d'après Thompson et Kiddy [19], la fraction $\beta$ d'après Aschaffenburg [3] et la fraction $\chi$ d'après Zittle et Custer [23]. Après purification, des fractions préparées étaient dissoutes en eau et lyophilisées. Pour l'analyse, la caséine et ses fractions étaient dissoutes en solution tampon composée de phosphate et d'acide citrique à pH $5,0,5,6,6,0$ et 7,0. Des solutions tampon étaient additionnées de $\mathrm{NaCl}$, à la concentration de $3 \mathrm{p} .100$, et de merthiolate, à la concentration de $0,025 \mathrm{mg} / \mathrm{ml}$, pour prévenir tout développement de la microflore indésirable.

Les substrats étaient ensemencés avec 10 p. 100 de la suspension des germes étudiés, en proportion volumétrique. La quantité de germes, ajoutés en suspension, était de $4.10^{\circ}$. Après l'incubation de $10 \mathrm{j}$ qui avait lieu à la température optimale de la souche étudiée, le tout était réparti en deux fractions, l'une étant soluble et l'autre insoluble à $\mathrm{pH} \mathrm{4,6.} \mathrm{Dans} \mathrm{la} \mathrm{fraction} \mathrm{qui} \mathrm{était} \mathrm{soluble} \mathrm{à} \mathrm{pH} \mathrm{4,6}$ on déterminait la teneur en azote, par la micro-méthode de Kjeldahl, ainsi que celle en azote de groupes disponibles $\alpha-\mathrm{NH}_{2}$, par la méthode de Kainz, rapportée par Alexander et Block [1]. 
La fraction insoluble à pH 4,6 était partagée par électrophorèse sur gel d'amidon, en utilisant la méthode de Wake et Baldwin [21] et chromatographiée sur DEAE-cellulose, en faisant usage de la méthode qui avait été mise au point par Mercier et al. [12] pour le partage de la caséine isoélectrique.

\section{RESULTATS ET DISCUSSION}

En appréciant, sur la base des résultats obtenus, le degré d'hydrolyse de la caséine $\alpha_{s}, \beta$ et $\chi$, effectuée par la suspension de germes de St. lactis $\mathrm{T}_{1}$, Str. diacetilactis 157 et Str. cremoris 319 , on voit clairement que des fractions particulières de la caséine étaient décomposées par les souches examinées avec une intensité diverse.

En comparant, après incubation, les accroissements du $\mathrm{N}$ soluble à $\mathrm{pH} 4,6$ et du $\mathrm{N}$ des groupes $\alpha$ aminés disponibles (tab. 1) on observait que, de toutes les fractions analysées, c'était la $\chi$-caséine qui était décomposée de la manière la plus intense par des suspensions de germes de Str. lactis $\mathrm{T}_{1}$ et Str. diacetilactis 157 . La protéolyse de la

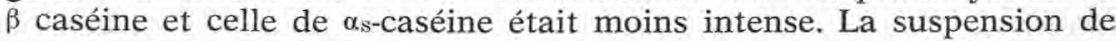
Str. cremoris 319 libérait les quantités les plus élevées de $\mathrm{N}$ soluble et de $\mathrm{N}$ des groupes disponibles $\alpha-\mathrm{NH}_{2}$ à partir de la $\beta$-caséine, et des quantités moins élevées de ces combinaisons à partir de la $\chi$ et as caséine.

L'effet du $\mathrm{pH}$ du substrat sur les propriétés protéolytiques des souches étudiées s'était manifesté d'une manière aussi évidente. La suspension des germes de Str. lactis révélait son activité protéolytique maximale dans le cas de $\alpha_{s}$ caséine à $\mathrm{pH} 6,0$ et 7,0 tandis que la dégradation de la $\beta$ et $\chi$-caséine était la plus forte à $\mathrm{pH} 5,6$ et 7,0. La souche de Str. diacetilactis aboutit à l'optimum de ses aptitudes protéolytiques dans le cas de $\alpha_{s}$-caséine, tandis que pour la $\beta$ et $\chi$-caséine, l'optimum se manifestait à $\mathrm{pH} 5,6$. Chez Str. cremoris, la décomposition de $\alpha_{\mathrm{s}}$-caséine était la plus intense à $\mathrm{pH} 5,0$ et 5,6 , celle de la $\beta$-caséine l'était à $\mathrm{pH} 7,0$ et 5,6 et celle de la caséine $\chi$ à $\mathrm{pH} 6,0$.

On peut surtout remarquer que, malgré toutes les différences observées pour toutes les fractions de la caséine, deux points optimaux manifestes de l'activité protéolytique maximale étaient présents, dont le plus élevé à $\mathrm{pH} 5,6$ et l'autre, le moins élevé, à $\mathrm{pH} 7,0$. Nos résultats sont en accord avec ceux de Van der Zant et al. [22], Baribo et Foster [4] et Budslawski et al. [5], qui ont constaté l'existence de ces deux points optimaux de l'activité protéolytique des bactéries lactiques pour la protéolyse des protéines de lait ou celle des préparations de caséine.

Les résultats de ces expériences diffèrent de ceux que nous avons obtenus dans des essais préliminaires sur la protéolyse de la $\chi$-caséine, effectuée par la suspension des mêmes bactéries. La suspension de 
TABLEAU 1. - Teneur en N-soluble à pH 4.6 (en p. 100 de N-total) et en groupes disponibles $\alpha$ - $\mathrm{NH}_{2}$ de la fraction soluble à $\mathrm{pH} 4.6$ (en $\mathrm{mg} \mathrm{N}$ ) des fractions de caséine après l'incubation avec la suspension de germes des bactéries

\begin{tabular}{|c|c|c|c|c|c|c|c|}
\hline \multirow{2}{*}{$\begin{array}{l}\text { Fractions } \\
\text { de la caséine }\end{array}$} & \multirow{2}{*}{$\underset{\mathrm{pH}}{\mathrm{du} \text { substrat }}$} & \multicolumn{2}{|c|}{ Str. lactis $\mathrm{T}_{1}$} & \multicolumn{2}{|c|}{ Str. diacetilactis 157} & \multicolumn{2}{|c|}{ Str. cremoris 319} \\
\hline & & N-soluble & $\mathrm{N}-\alpha-\mathrm{NH}_{2}$ & $\mathrm{~N}$-soluble & $\mathrm{N}-\alpha-\mathrm{NH}_{2}$ & N-soluble & $\mathrm{N}-\alpha-\mathrm{NH}_{2}$ \\
\hline$\alpha_{\mathrm{s}}$ & $\begin{array}{l}5.0 \\
5.6 \\
6.0 \\
7.0\end{array}$ & $\begin{array}{l}20.52 \\
22.97 \\
34.86 \\
32.78\end{array}$ & $\begin{array}{l}0.602 \\
0.841 \\
0.746 \\
0.746\end{array}$ & $\begin{array}{l}19.25 \\
46.86 \\
58.02 \\
51.00\end{array}$ & $\begin{array}{l}1.285 \\
1.514 \\
1.829 \\
1.686\end{array}$ & $\begin{array}{l}14.83 \\
19.87 \\
17.62 \\
18.94\end{array}$ & $\begin{array}{l}0.360 \\
0.475 \\
0.578 \\
0.544\end{array}$ \\
\hline$\beta$ & $\begin{array}{l}5.0 \\
5.6 \\
6.0 \\
7.0\end{array}$ & $\begin{array}{l}20.17 \\
29.56 \\
23.26 \\
27.38\end{array}$ & $\begin{array}{l}0.494 \\
0.814 \\
0.843 \\
0.610\end{array}$ & $\begin{array}{l}25.46 \\
71.68 \\
59.57 \\
39.39\end{array}$ & $\begin{array}{l}0.798 \\
1.937 \\
1.728 \\
1.237\end{array}$ & $\begin{array}{l}15.86 \\
23.25 \\
15.83 \\
16.38\end{array}$ & $\begin{array}{l}0.325 \\
0.136 \\
0.154 \\
0.327\end{array}$ \\
\hline$\chi$ & $\begin{array}{l}5.0 \\
5.6 \\
6.0 \\
7.0\end{array}$ & $\begin{array}{l}31.35 \\
36.50 \\
29.19 \\
33.31\end{array}$ & $\begin{array}{l}0.875 \\
1.050 \\
0.963 \\
0.732\end{array}$ & $\begin{array}{l}45.17 \\
53.84 \\
47.91 \\
53.38\end{array}$ & $\begin{array}{l}1.324 \\
1.785 \\
1.756 \\
1.692\end{array}$ & $\begin{array}{l}20.74 \\
23.29 \\
25.74 \\
24.86\end{array}$ & $\begin{array}{l}0.841 \\
0.886 \\
1.104 \\
1.000\end{array}$ \\
\hline
\end{tabular}




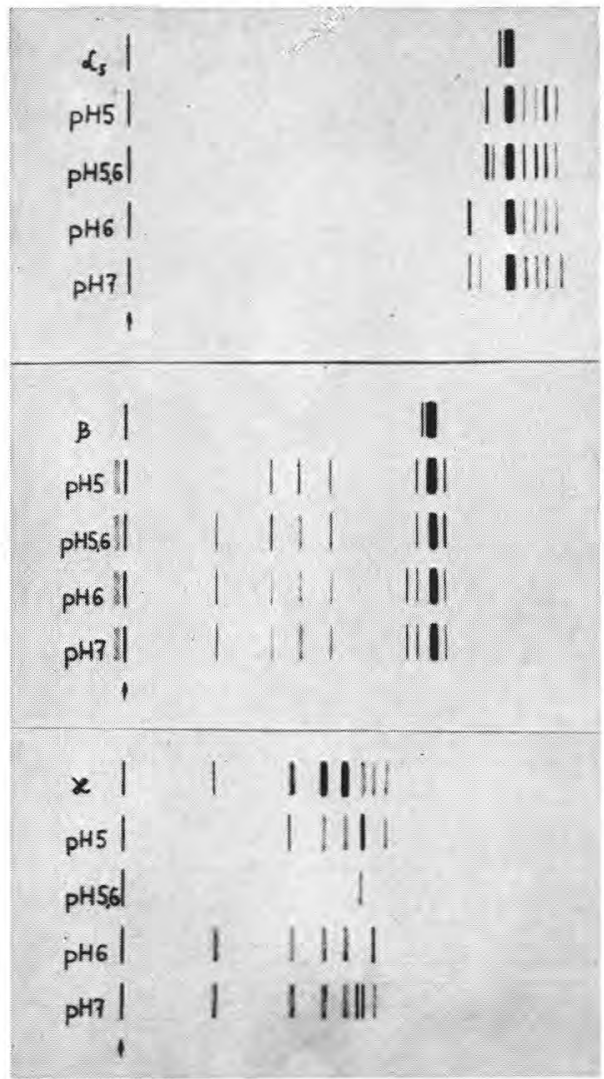

fig. 1

Distribution électrophorétique sur gel d'amidon de la fraction de $\alpha_{\mathrm{s}}(\mathrm{a}), \beta$ (b) et $\chi$-caséine (c) insoluble à $\mathrm{pH} 4,6$ après l'incubation avec la suspension de germes Str. lactis $\mathrm{T}_{1}$.

germes de Str. diacetilactis avait montré alors le pouvoir plutôt faible de libérer des groupes $\alpha$-aminés disponibles. Ces différences résultent probablement du fait que, dans l'expérimentation présente, 3 p. 100 de $\mathrm{NaCl}$ était ajouté au tampon qui servait à dissoudre les fractions de caséine. A cette concentration, le chlorure de sodium pouvait être un facteur qui influençait favorablement le procédé de la protéolyse, en rendant plus facile la lyse des germes morts et la sécrétion des enzymes intracellulaires. Stadhouders [18] a étudié l'effet de la concentration du chlorure de sodium sur l'activité protéolytique de la présure et a démontré que la teneur du substrat en $\mathrm{NaCl}$ de 3 p. 100 avait l'effet le plus stimulant sur le degré de protéolyse des protéines du lait. On trouverait une certaine analogie entre 

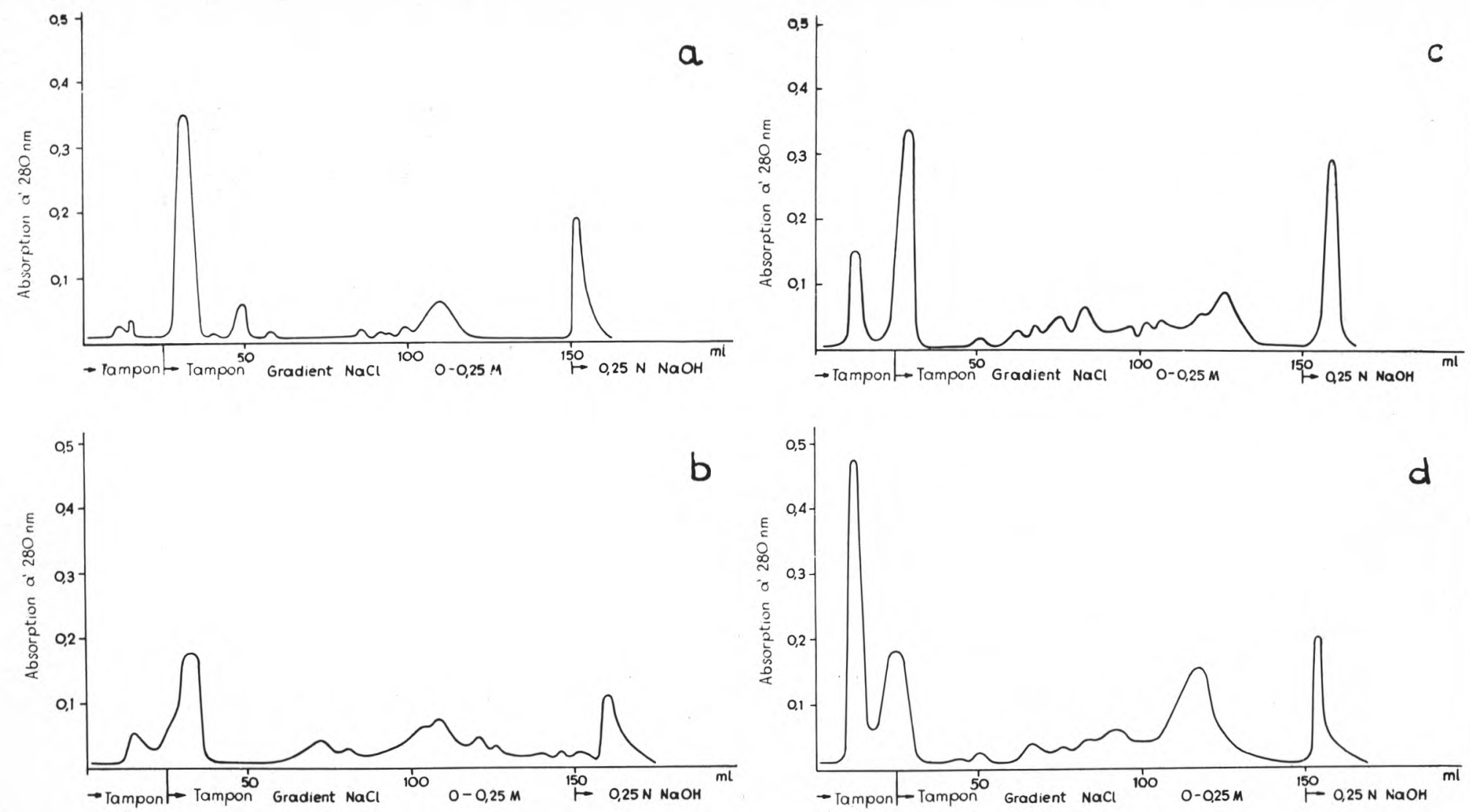

fig. 2

Chromatogrammes de la distribution des fractions de caséine, insoluble à $\mathrm{pH}$ 4,6, après l'incubation avec suspension de germes

$\begin{array}{llll}\text { a) } \alpha_{\mathrm{s}} \text {-caséine à } \mathrm{pH} 5,0 & \text { b) } \alpha_{\mathrm{s}} \text {-caséine à } \mathrm{pH} 5,6 & \text { c) } \beta \text {-caséine à } \mathrm{pH} 5,0 & \text { d) } \beta \text {-caséine à } \mathrm{pH} 5,6 \\ \text { Colonne DEAE-cellulose, diamètre } 1 \mathrm{~cm} \text {, longueur } 20 \mathrm{~cm} \text {. Tampon : urée } 3,3 \mathrm{M} \text {, imidasol } 0,02 \mathrm{M}, \mathrm{HCl}, \mathrm{pH} 7,0 \text {. Vitesse de passage : }\end{array}$ de Str. lactis $\mathrm{T}_{1}$

$7 \mathrm{ml} / \mathrm{h}$, fraction $2 \mathrm{ml}$. 
ces données de Stadhouders et les résultats, concernant l'effet stimulant du chlorure de sodium sur l'activité des enzymes protéolytiques de la présure et des bactéries lactiques, que nous avons présentés ci-dessus. En même temps, on ne peut exclure l'influence partielle de la composition du milieu (hydrolyse des protéines de lactosérum, addition de l'extrait de levure et d'ions de Mn) sur le système de l'appareil enzymatique des bactéries qui y sont cultivées. Le changement des propriétés protéolytiques des bactéries lactiques dû à la composition du milieu de culture a été signalé par plusieurs auteurs [10]. Des variations de l'activité protéolytique des souches de bactéries étudiées que nous avons présentées n'ont pas trouvé de reflet aussi distinct dans le partage électrophorétique sur gel d'amidon des fractions de caséines insolubles à pH 4,6 (fig. 1).

Des électrophorégrammes n'indiquaient de différences essentielles ni entre les souches, ni dues aux valeurs différentes du $\mathrm{pH}$ du substrat. Ce n'est pas que des partages électrophorétiques de la $\%$ et $\beta$-caséines incubées avec Str. lactis qui différaient des autres électrophorégrammes.

Parmi les fractions diverses de la caséine, c'était la $\beta$-caséine qui était dégradée avec la plus grande intensité, ce qui vaut pour toutes les trois souches analysées. Différents des produits de la protéolyse de $\alpha_{\mathrm{s}}$-caséine, les produits de protéolyse de la $\beta$-caséine se caractérisaient par une mobilité électrophorétique beaucoup moins élevée et des fractions peptidiques plus nombreuses, en comparaison avec les fractions enzymatiquement intactes. En comparant les souches utilisées selon leur électrophorégrammes, certaines différences peuvent être observées entre elles quant au degré de protéolyse de la $\chi$-caséine, et, de façon moins remarquable, celui de $\alpha_{\text {s-caséine. }}$

L'interprétation des résultats obtenus a été rendue un peu difficile par le fait que l'intensité de la coloration des fractions peptidiques ne dépend pas toujours de la quantité du peptide en question. On sait bien que le pouvoir du noir amido de lier les protéines et les peptides dépend des acides aminés terminaux, tels que la lysine, l'arginine et l'histidine [11] et que les enzymes protéolytiques sont capables de différencier ces acides aminés au cours de la décomposition des protéines [15].

Différant des résultats des distributions électrophorétiques, les distributions chromatographiques sur DEAE-cellulose sont différenciées selon les fractions des caséines, tout en se distinguant aussi par rapport à la souche utilisée et au $\mathrm{pH}$ du substrat.

Les distributions chromatographiques qui étaient obtenues après incubation des fractions de caséine avec la suspension des germes de Str. cremoris (fig. 4) étaient semblables à celles des fractions de $\alpha_{\&}$ et $\beta$-caséine enzymatiquement intactes ( $=$ non attaquées par des enzymes), Cela prouve que la structure de ces fractions de protéine n'est changée que bien peu après l'incubation, et en même temps que les pouvoirs protéolytiques des enzymes de la souche de Str. cremoris 319 

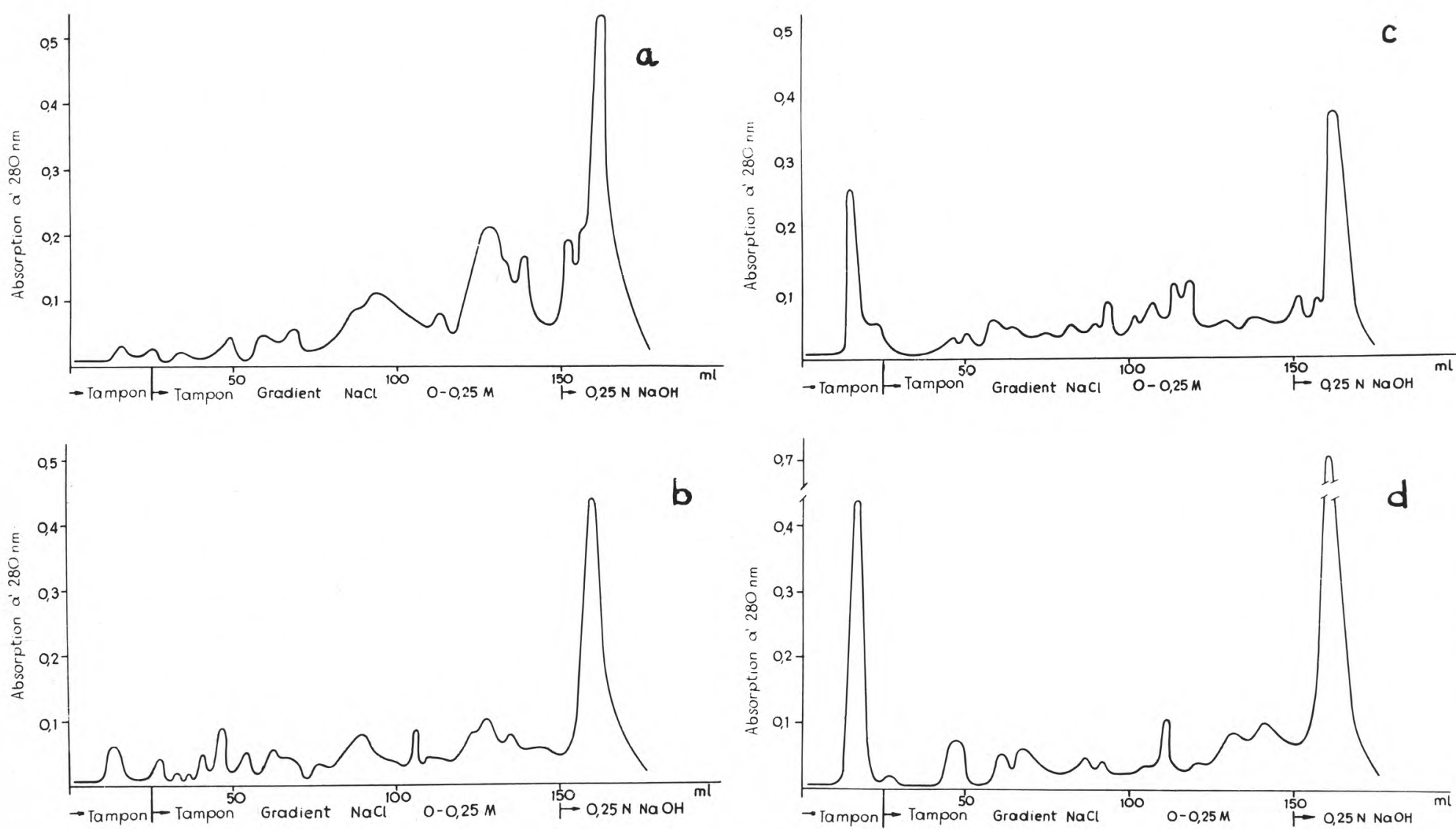

fig. 3

Chromatogrammes de la distribution des fractions de caséine, insoluble à pH 4,6, après l'incubation avec suspension de germes de Str. diacetilactis 157
a) $\alpha$ s-caséine à pH 5,0
b) $\alpha_{\mathrm{s}}$-caséine à $\mathrm{pH} 5,6$
c) $\beta$-caséine à pH 5,0
d) $\beta$-caséine à $\mathrm{pH} 5,6$

Conditions de distribution v. fig. 2 . 
étaient limités. Le partage de $\alpha_{s}$ et $\beta$-caséine qui était effectué après incubation avec la suspension de germes de Str. lactis $\mathrm{T}_{1}$ (fig. 2) montre, au contraire, que l'élution rapide du premier état indique un changement structural essentiel qui avait lieu au cours de l'incubation (faibles forces de liaison entre la surface d'une molécule de protéine et la surface de l'adsorbant).

Des modifications structurales de protéines ayant un caractère un peu différent étaient observées après incubation avec la souche de Str. diacetilactis 157 (fig. 3). En ce cas, de grandes quantités de protéines qui ne pouvaient être éluées qu'avec la solution $0,25 \mathrm{~N}$ de $\mathrm{NaOH}$ indiquent que des forces de liaison de la molécule de protéine et de l'adsorbant étaient très élevées.

Outre des différences essentielles dans les distributions chromatographiques de $\alpha_{s}$ et $\beta$-caséine après incubation avec des suspensions de germes des souches étudiées, quelques propriétés communes peuvent être également observées. Indépendamment de la souche étudiée, la distribution de la $\beta$-caséine est caractérisée par l'élution de grandes quantités de protéines qui avait lieu déjà avant que le degré de concentration fût employé, tandis que dans la distribution de $\alpha_{\text {s-caséine }}$ des quantités, de protéines éluées étaient très basses avant que le degré de concentration fût employé.

Des différences entre les distributions chromatographiques de $\alpha_{s}$ et $\beta$-caséine indiquent, en comparaison avec les résultats des déterminations du $\mathrm{N}$ soluble en du $\mathrm{N}$ des groupes disponibles $\alpha-\mathrm{NH}_{2}$, indiquent un procédé bien différencié de protéolyse, par rapport au $\mathrm{pH}$ du substrat. En même temps, les résultats des distributions chromatographiques ont démontré que les pouvoirs les plus élevés de la dégradation de $\alpha_{s}$ et $\beta$-caséine étaient observés chez les souches de Str. lactis $\mathrm{T}_{1}$ et Str. diacetilactis 157, tandis que la souche Str. cremoris 318 possédait des pouvoirs moins élevés de dégradation des fractions de caséine.

Outre cela, des résultats obtenus indiquent clairement que les souches de bactéries lactiques étudiées effectuaient la décomposition de la caséine d'une manière qui semble caractéristique pour elles. Cela prouve qu'elles possédaient un système différencié des peptidohydrolases. Nos résultats étaient confirmés aussi par des schémas de la séparation électrophorétique des peptides, obtenus à partir de la fraction de $\chi$-caséine, digérée par la trypsine, après incubation avec la suspension de germes de mêmes souches (Rymaszewski, Poznanski [15]). Le système différencié de l'appareil enzymatique des bactéries lactiques et leur pouvoir de dégrader les protéines du lait, avec formation de produits de protéolyse différant par leur poids moléculaire, ont été rapportés par Klimowski et al. [9 a, b], Sirhaug et Solberg [17] et les autres [10].

Les aptitudes protéolytiques plus élevées de souches Str. lactis $\mathrm{T}_{1}$ et de Str. diacetilactis 157 sont de même confirmées par des résultats, si peu exacts qu'ils soient, concernant les distributions électrophorétiques de la caséine isoélectrique après incubation avec les suspen- 

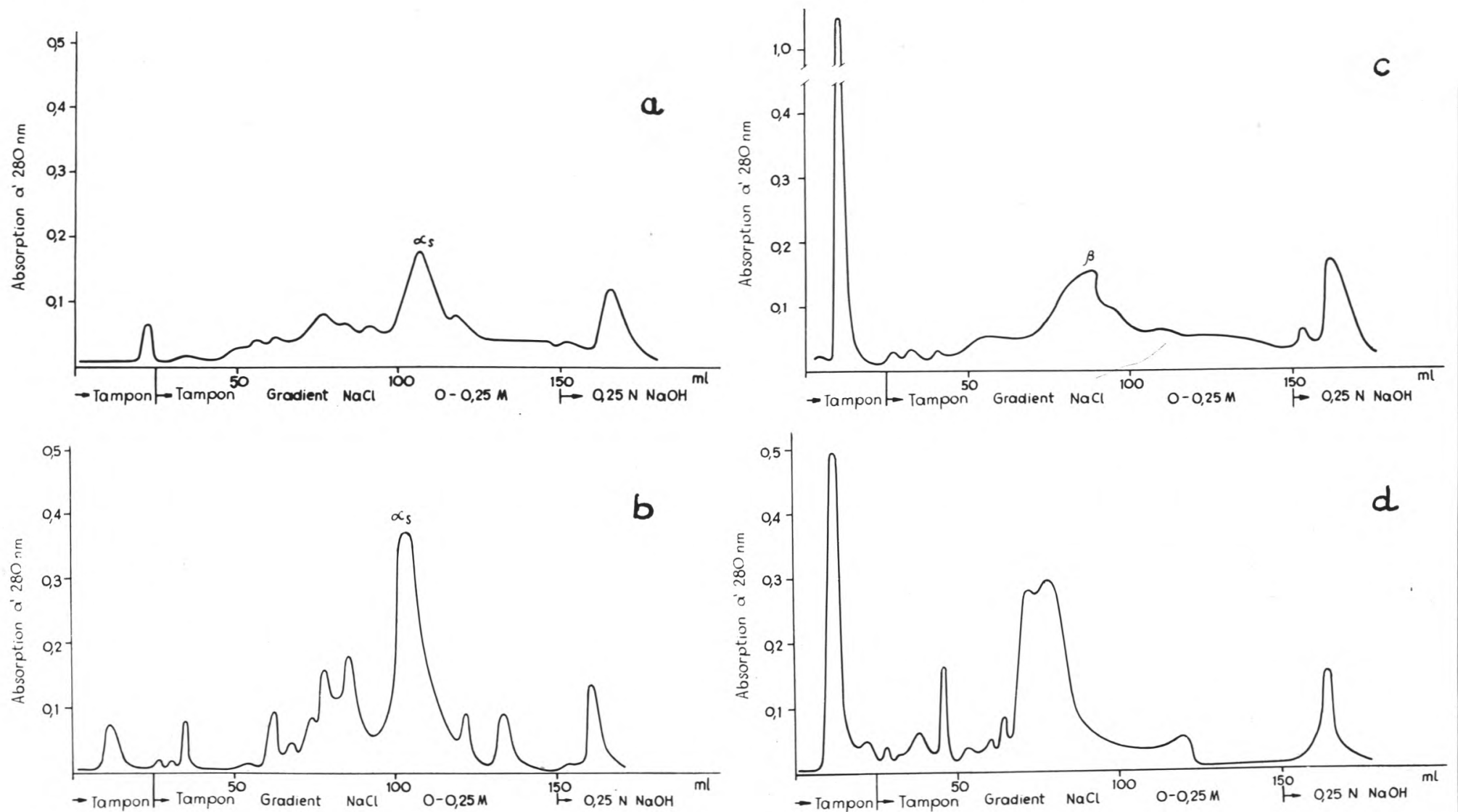

fig. 4

Chromatogrammes de la distribution des fractions de caséines, insolubles à pH 4,6, après l'incubation avec suspension de germes $\begin{array}{ll}\text { a) } \alpha_{\mathbb{S}} \text {-caséine à } \mathrm{pH} 5,0 & \text { b) } \alpha_{\mathbb{S}} \text {-caséine à } \mathrm{pH} 5,6\end{array}$ de Str. cremoris 319

Conditions de distribution v. fig. 2.
c) $\beta$-caséine à pH 5,0
d) $\beta$-caséine à pH 5,6 
a)

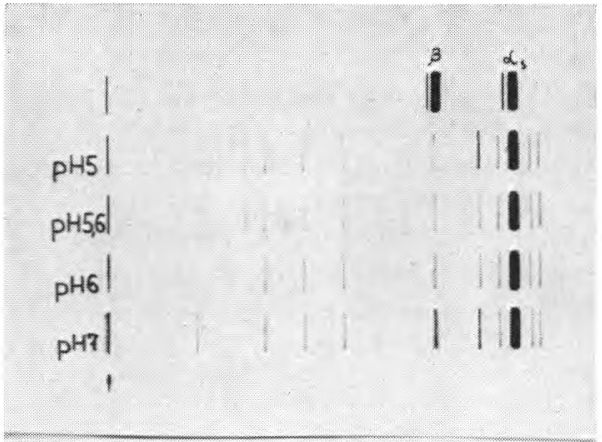

b)

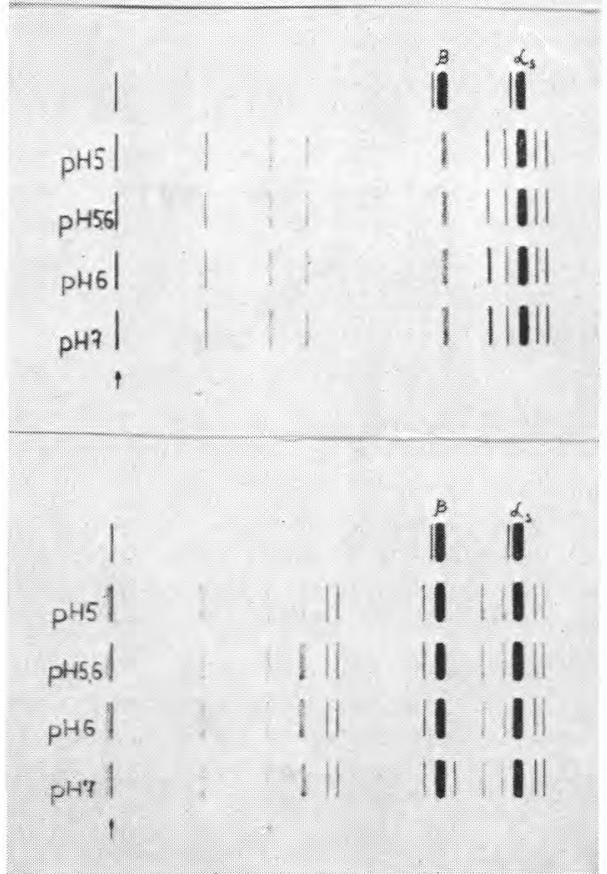

fig. 5

Distribution électrophorétique sur gel d'amidon de la fraction isoélectrique, insoluble à $\mathrm{pH} 4,6$, après l'incubation avec la suspension de germes:
a) Str. lactis $\mathrm{T}_{1}$
b) Str. diacetilactis 157
c) Str. cremoris 319 
sions de germes des souches analysées (fig. 5). Nos observations sont d'accord encore une fois, avec les données de Budslawski et al. [5] qui ont constaté, sur la base de l'accroissement de la teneur en produits divers de protéolyse, le pouvoir assez universel de la souche de Str. lactis $\mathrm{T}_{1}$ d'hydrolyser la caséine isoélectrique.

En même temps, les distributions électrophorétiques démontrent que la dégradation de $\beta$-caséine était plus intense que celle de $\alpha_{s}$-caséine. Cela est confirmé aussi par des partages de la $\beta$-caséine où l'on a constaté la décomposition plus intense que pour les autres fractions. De même, le complexe de 4-5 fractions, caractérisé par une mobilité électrophorétique bien basse, a été trouvé dans des distributions de la $\beta$-caséine et celles de la caséine isoélectrique, ce qui suggérait, que ces fractions provenaient de la dégradation de la $\beta$-caséine.

Le phénomène de la dégradation de la $\beta$-caséine, plus intense par

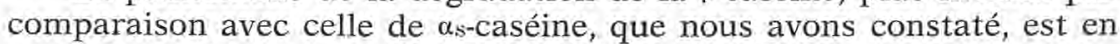
accord avec les résultats de Dyatchenko et al. [6]. En même temps, les résultats de nos études présentent une certaine analogie avec ceux de Fox et Valley $[7,8]$ qui ont étudié récemment la décomposition de $\alpha_{s}$ et $\beta$-caséine par la présure et la pepsine. Ces auteurs qui ont utilisé l'électrophorèse sur gel d'amidon, étaient d'avis que la présure attaquait $\alpha$ s-caséine d'une manière différente, en comparaison avec la

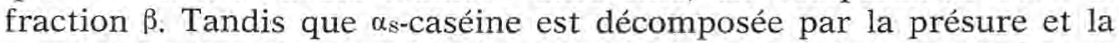
pepsine en grande quantité des combinaisons azotiques solubles en acide trichloracétique à 12 p. 100, la $\beta$-caséine est décomposée en fragments peptidiques de poids moléculaire relativement élevé, insolubles en acide trichloracétique à 12 p. 100 . Des différences semblables que nous avons constatées dans le caractère de la protéolyse de $\alpha_{\text {s }}$ et $\beta$-caséine indiquent non seulement la nature variée de l'appareil enzymatique des souches étudiées, mais aussi le fait que les enzymes des bactéries lactiques révèlent une spécificité apparente de leur façon de décomposer $\alpha$ s et $\beta$-caséine. Sur la vue des résultats obtenus, il apparaît que l'appréciation de l'activité protéolytique des bactéries lactiques doit être basée non seulement sur les résultats de l'accroissement des combinaisons solubles dans l'eau, mais aussi sur les résultats des séparations électrophorétiques et chromatographiques des combinaisons insolubles. Il faut rechercher également si des peptides provenant de la $\beta$-caséine, de poids moléculaire élevé, solubles en acide trichloracétique à 12 p. 100 , ne produisent pas une saveur amère. La connaissance plus complète de la nature des peptides qui sont libérés par des souches diverses, ainsi que celle de leurs propriétés particulières de goût permettraient la sélection consciente des souches pour la production des fromages, ainsi que la différenciation plus précise des diverses sortes de fromages. Il apparaît que la méthode que nous avons choisie, celle de la séparation chromatographique des produits de dégradation des protéines de fromage, accompagnée de leur caractéristique plus détaillée, peut se montrer bien utile pour réaliser ces objectifs. 


\section{Ré s u m é}

Sur la base des accroissements de l'azote, soluble à $\mathrm{pH} 4,6$, des groupes disponibles de $\alpha-\mathrm{NH}_{2}$, de la distribution électrophorétique sur gel d'amidon et la distribution chromatographique sur DEAE-cellulose, on a examiné le degré de protéolyse des caséines : isoélectrique, $\alpha_{s}, \beta$ et $\chi$, dégradées par des suspensions de germes lactiques.

On a constaté que, de toutes les souches analysées, ce sont celles de Str. lactis $\mathrm{T}_{1}$ et Str. diacetilactis 157 qui possédaient l'activité protéolytique la plus élevée, tandis que celle de Str. cremoris 157 était beaucoup plus faible.

Parmi des fractions de la caséine totale, ce sont celles de $\beta$ et $\chi$ dont la décomposition paraissait la plus intense, bien plus que celle de la fraction $\alpha_{\mathrm{s}}$.

Les enzymes des souches des bactéries analysées possédaient une aptitude différenciée à la protéolyse des fractions de caséine en relation avec le $\mathrm{pH}$ du substrat. On a constaté deux sphères d'activité protéolytique maximale, l'une à $\mathrm{pH} 5,6$ et l'autre à $\mathrm{pH} 7,0$.

La nature variée des produits de protéolyse de la caséine et de ses fractions indique que l'appareil enzymatique des souches de Str. lactis $\mathrm{T}_{1}$ et $\mathrm{Str}$. diacetilactis 157 était pourvu d'un système différencié de peptidohydrolases révélant un effet spécifique envers les diverses fractions de caséine.

La chromatographie sur DEAE-cellulose s'est montrée préférable pour étudier le degré de dégradation des fractions de caséine, en comparaison avec l'électrophorèse sur gel d'amidon.

\section{S u m m a ry}

On the basis of increased nitrogen amounts, as soluble at $\mathrm{pH} 4.6$, available $\alpha-\mathrm{NH}_{2}$ groupe nitrogen, starch-gel electrophoretic distribution and DEAE-cellulose chromatographic distribution, the degree of proteolysis was investigated, for isoelectric, $\alpha_{\mathrm{s}}, \beta$ and $\chi$ caseins, as degraded by germ suspension of lactic acid bacteria.

Of all strain analysed, the strains of Str. lactis $\mathrm{T}_{1}$ and Str. diacetilactis 157 were found to possess the highest proteolytic activity, while the activity of the Str. cremoris strain 319 was much lower.

Within the total casein fraction, the $\beta$ and $\chi$ fractions were degraded with the highest intensity, while the degradation of $\alpha_{s}$-casein was much weaker.

Enzymes of bacterial strains analysed possessed differentiatied proteolytic ability for various casein fractions, as related to $\mathrm{pH}$ values of substrate. 
Two ranges of maximum proteolytic activity were found to be present, at pH 5.6 and $\mathrm{pH} 7.0$ respectively.

The various nature of proteolysis products of casein and its fractions indicate that the strains of Str. lactis $\mathrm{T}_{1}$ and Str. diacetilactis 157 are provided with enzyme apparatus involving a differentiated system of peptidohydrolases which have a specific effect on individual casein fractions.

The DEAE-cellulose chromatography appeared to be more effective than the starch-gel electrophoresis was for investigating the degradation extent of casein fractions.

\section{Bibliographie}

[1] Alexander (P.) and Block (R.) (1960). - Analytical Methods of Protein Chemistry. Pergamon Press, New-York, 2, 63.

[2] Amunstadt (O.) (1950). - Recherche sur l'activité protéolytique de la présure et de quelques bactéries lactiques notamment en ce qui concerne la maturation du fromage. Meddeland Frau Statens Mejeri Forsok, Malmö 28.

[3] Aschaffenburg (R.) (1963). - Preparation of $\beta$-casein by a modiefied urea fractionation method. J. Dairy Res, 30, 259

[4] BARIBo (E.), Foster (E. M.) (1952). - The intracellular proteinases of certain organisms and their relationship to the proteinase in cheese. J. Dairy Sci., 35, 149.

[5] Budslawski (J.), Bondar (J.), Damicz (W.), Markiewicz (K.) (1969) .- Badanie aktywnosci proteolitycznej enzymow wewnatrzkomorkowych niektorych paciorkowcow mlekowych. Zesz. Nauk. WSR Olszt., 25, 3.

[6] Dyachenko (P. F.), Shidlovskaya (V. P.) (1970). - Proteolytic activity of lactic acid bacteria. Trudy vses. nauchnoissled. Inst. moloch. Prom., $27,9$.

[7] Fox (P. F.) (1969). - Influence of temperature and $\mathrm{pH}$ on the proteolytic activity of Rennet Extract. J. Dairy Sci., 52, 1214.

[8] Fox (P. F.) and Valley (B. F.) (1971). - Influence of sodium chloride on the proteolysis of casein by rennet and by pepsin. J. Dairy Res., 38, 165.

[9a] Klimowskiu (I. I.), Zwagincew (W. I.), GudKow (W.A.) (1969). - Zrawnitielnoje izuczenije produktow proteoliza razlicznymi szlamami molocznokislych streptokokkow. Moloch. Prom., 5, 26.

[9b] KlimowskiJ (I. I.), ZWAgincew (W. I.), GudKow (W. A.) (1969). - Osobiennosti proteoliza bielkow moloka razlicznymi szlamami molocznokislych streptokokkow. Moloch. Prom., 6, 10.

[10] Libudisz (Z.), Metodiewa (D.) (1970). - Trawienie kazeiny i jej frakcji przez enzymy proteolityczne Str. lactis i Str. diacetilactis. Rocz. Techn. Chemii Zywn. XIX, 48.

[11] Manson (W.) (1966), - The reaction of casein with the basic dye-Safranine. XVII Int. Dairy Congress, D2, 193.

[12] Mercier (J. C.), Maubois (J. L.), Poznanski (S.), et Ribadeau-Dumas (B.) (1968). - Fractionnement préparatif des caséines de vache et de brebis par chromatographie sur DEAE-cellulose en milieu urée et 2-mercaptoéthanol. Bull. Soc. Chim. Biol., 50, 34. 
[13] Poznanski (S.), Lenoir (J.), et Mocouot (G.) (1965). - La protéolyse de la caséine par les enzymes intracellulaires de certaines bactéries. Le Lait, 441-442, 3.

[14] Ribadeau-Dumas (B.), Maubois (J. L.), Mocouot (G.) et Garnter (J.) (1964). Etude de la constitution de la caséine de vache par chromatographie sur colonnes de diéthylaminoéthyl-cellulose en milieu urée. Biochim. Bioph. Acta, 8, 494.

[15] Rymaszewski (J.), Poznanski (S.) (1968). - The breadkdown of $\chi$-casein components by cell suspensions of lactic acid bacteria. Bull. de l'Académie Polonaise des Sciences, XVI, 10, 609.

[16] Rymaszewski (J.), Poznanski (S.), Maginska (Cz.) (1971). - Utilisation de la biomasse des bactéries de la fermentation lactique pour la fabrication des fromages. Le Lait, 501-502, 23.

[17] Sirhang (T.) and Solberg (P.) (1970). - Esterases and proteinases from acetone-dried lactic acid bacteria. XVII Int. Dairy Congress, 1E, 116.

[18] Stadhouders (J.) (1962). - The proteolytic activity of rennet and starter bacteria in cheese with reference to bitter flavour. XVI Int. Dairy Congress, $B, 679$.

[19] Thompson (M. P.), KIDDY (C. A.) (1964). - Genetic polymorphism in casein of cow's milk. III. Isolation and properties of $\alpha_{\mathrm{s}}$-casein A, B and C. J. Dairy Sci., 47, 626.

[20] Valles (E.), Mocouot (G.) (1968). - Préparation de suspensions concentrées et congelées de bactéries lactiques thermophiles destinées à la fromagerie. Le Lait, 479-480, 631.

[21] WAKE (R.) and BALDWIN (R. L.) (1961). - Analysis of casein fractions by zone elektrophoresis in concentrated urea. Biochim. Biophys. Acta, 47, 225.

[22] Zant VAN DeR (V.C.) and Nelson (F. E.) (1953). - Characteristics of endocellular proteolytic enzyme system of Streptococcus lactis. J. Dairy Sci., 37, 1213.

[23] Zittle (C.A.) and Custer (J.M.) (1963). - Preparation and some of the

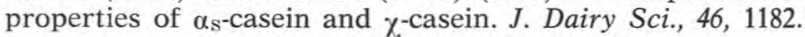

